\title{
Global scholarship \\ The role of subject repositories in advancing research from the developing world
}

W

hile subject repositories successfully fill a scholarly communication niche in particular disciplines, they have not been recognized for the important role they play in promoting global scholarship. Repositories such as AgEcon Search ${ }^{1}$ make valuable and unique contributions by increasing publishing options for researchers and thus exposing and distributing research produced in the developing world.

\section{Global publishing landscape}

The bias toward the Western world in the publishing arena has been well documented. Many rankings (e.g., journal impact factors) are calculated using data from Thomson Reuters (Web of Science) or other Westernbased entities that include only a fraction of the total corpus of published works. A recent study found a clear correlation between gross domestic product (GDP) and both journal placement and citation performance. ${ }^{2}$ This bias confers a negative impact on the advancement of research in and about the developing world, since "access to scholarly information from the developed global North does not necessarily provide relevant knowledge pertaining to context-specific issues in Africa." 3

Investigation of why this bias exists reveals serious challenges in publishing research conducted in the developing world and in discovering it once it has been published.
The challenges include:

- domination of academic publishing by companies and organizations based in (and largely representing) North America and Western Europe;

- significant pressure in the developing world to publish in journals published in the developed world, particularly in journals indexed by Web of Science; ${ }^{4}$

- editorial bias against article submissions from the developing world; 5

- page charges, which "even with a waiver, put off would-be authors"; ${ }^{6}$

- African universities may not reward research efforts, and early career researchers struggle to publish due to heavy teaching and administrative workloads; ${ }^{7}$

- “...weak representation of less-developed countries on [Northern] editorial boards" $;$ and

- The diaspora effect, whereby many researchers settle (and publish) in the developed world rather than returning to their

Julia Kelly is research and instruction librarian, email: jkelly@umn.edu, and Linda Eells is research librarian, email: Ile@umn.edu, at the University of Minnesota

Contact series editors Zach Coble, digital scholarship specialist at New York University, and Adrian Ho, director of digital scholarship at the University of Kentucky Libraries, at crlnscholcomm@gmail.com with article ideas

๑ 2015 Julia Kelly and Linda Eells 
home countries and publishing research there. ${ }^{9}$ This potentially reduces the amount of research that could be published, albeit subject to the barriers listed above.

These barriers result in a lopsided, one-way movement of information from the developed to the developing world. This is an information transfer rather than an exchange, and it makes highlighting work from the developing world a challenge.

\section{Solutions}

Open access venues hold promise for addressing a number of these issues, but they are in the early stages of development in many regions. Open access efforts are still fragmented in Africa, and this model is not yet widely recognized or accepted by policymakers. ${ }^{10}$ While more and more universities in developing countries are building institutional repositories, they appear to encounter the same technological, cultural, and resource struggles that are common in other parts of the world. ${ }^{11}$

Other projects hold promise for more widely disseminating research from the developing world. These include African Journals OnLine (AJOL), ${ }^{12}$ based in South Africa, which currently includes 491 peer-reviewed journals, some open access and some subscriptionbased. Sister projects launched by the nonprofit INASP ${ }^{13}$ include efforts in Bangladesh, Latin America, Mongolia, Nepal, and Sri Lanka. Another multi-country effort, SciELO ${ }^{14}$ (Scientific Electronic Library Online), makes journal literature from 12 Latin American countries and South Africa available online.

While all of these efforts are helping to expose research from the developing world, more needs to be done, and subject repositories can help. Leslie Chan and Barbara Kirsop note that repositories enable researchers in developing countries to reduce the south to north knowledge gap, "contribut[ing] to the global knowledge base by archiving their own research literature." 15

\section{AgEcon Search: A success story}

AgEcon Search exemplifies a successful subject repository model that could be leveraged in other disciplines. AgEcon Search is a freeto-use Internet resource with full-text working papers, conference papers, and journals in agricultural, development, energy, environment, resource, and other areas of applied economics. Initiated in 1995, it is housed at the University of Minnesota and cosponsored by the Agricultural and Applied Economics Association (AAEA). More than 250 institutions from 50 countries contribute their material to AgEcon Search, which currently contains more than 80,000 papers.

Although relatively small, this repository is widely recognized and valued by the international agricultural and applied economics community. Its success hinges largely upon the fact that agricultural economics has a rich culture of sharing preprints and grey literature (working papers, full conference papers, or reports). While reviews of subject repositories do not indicate specific factors for long-term success ${ }^{16}$ disciplines with this culture seem more open to a repository approach (e.g., arXiv). Authors regularly produce and share preprints with peers prior to the publication of a journal article. These preprints are recognized by researchers as an essential component of their academic literature.

AgEcon Search has taken a creative approach to resolving the challenges faced by repositories. Funding is frequently cited as a barrier to initiating and maintaining a repository. Contributing organizations upload their own papers or pay a small fee to have AgEcon Search upload for them. This is known to economists as a "distributed network," where many members of the community contribute for the good of the whole. This model greatly reduces the amount of labor required and enables AgEcon Search to succeed and grow on a very low budget. Some funding support has also been provided by groups interested in digitizing and adding their older print resources, with AgEcon Search coordinating the digitization process and providing lowcost uploading services with student labor.

Quality control can also be a challenge but, unlike some repositories, all papers in AgEcon Search must be part of a series, con- 
ference, or journal produced by an academic department, society, or organization that has already applied some level of review before the papers are deposited. Other repositories allow individual users to upload papers and depend on section editors or others to review each paper, a costly management expense AgEcon Search does not incur.

Finally, many repositories find it challenging to recruit content. Initially, academic societies and organizations needed to be convinced of the benefits of depositing their materials in AgEcon Search, such as greater discoverability and long-term preservation. Another benefit unique to AgEcon Search contributors is the added exposure papers received via inclusion in Research Papers in Economics (RePEc), ${ }^{17}$ a popular index covering economics that harvests all AgEcon Search content. Both RePEc and AgEcon Search are highly ranked by Google and Google Scholar. This added discoverability can help boost the careers of young researchers and promote journals and society publications.

These benefits and the growing corpus of material have earned this repository a reputation as the "go-to" resource for applied economists. Now, groups seek AgEcon Search out asking how they can get their papers into the repository.

\section{Global reach}

Many agricultural economics researchers in U.S. and Western European institutions work collaboratively with researchers in other parts of the world, which has helped to forge global connections. AgEcon Search exhibits at conferences in Africa, Australia, Asia, Latin America, and Europe have helped to bring in materials from societies, universities, government agencies, and nongovernment organizations from those regions.

In his discussion of information transfer versus information exchange, Williams E. Nwagwu notes that,

....if the dynamic character expected of [open access] in the globalizing world should occur, developed countries would be expected to consciously utilize their technology and other advantages to trigger counterbalance of their information export to developing countries. ${ }^{18}$

Although AgEcon Search is based in the United States, it has come to see the project as a global resource that provides a mechanism to offset the one-way movement of research from the developed world to developing countries. AgEcon Search has had success in adding materials from six continents. Examples from Africa include:

- The African Association of Agricultural Economists has included their conference papers since 2004 and its journal, African Journal of Agricultural and Resource Economics, since its inception in 2006.

- The University of Pretoria, Department of Agricultural Economics, Extension, and Rural Development began adding their working papers in 1998.

- The International Livestock Research Institute, part of the CGIAR ${ }^{19}$ Consortium with offices in Kenya and Ethiopia, has been including their research reports since 1990.

Another noteworthy example is the Collaborative Masters Programme (CMAP) sponsored by the African Economic Research Consortium, which connects programs at 14 universities in sub-Saharan Africa. CMAP has participated since 2007, and the 55 papers from its member institutions are among the most downloaded in AgEcon Search. Coordinators of CMAP have noted that having the papers available on the Internet is very important for those students interested in pursuing a $\mathrm{PhD}$, and one student was hired as a result of his employer seeing his thesis online.

\section{Conclusion}

Peter John Lor and Johannes J. Britz note that "the establishment of a sustainable, global knowledge society...can be achieved only when knowledge is effectively shared globally." ${ }^{20}$ Researchers in the least developed countries face serious challenges when disseminating their work, due to lack of 
resources as well as local and international publishing barriers. Librarians can fill a critical role in partnering with researchers and organizations in the developing world to address these challenges by building and maintaining repositories and by promoting a broad vision for their use. Through our understanding of the disciplines and each one's unique publication process, we can identify and pursue the most valuable content. Not only do the producers of the research benefit from greater exposure, but other researchers and students worldwide are able to discover the work and use it in their own research and teaching.

\section{Notes}

1. Agecon Search: http://ageconsearch. umn.edu/.

2. Matthew J. Smith, Cody Weinberger, Emilio M. Bruna, and Stefano Allesina, "The Scientific Impact of Nations: Journal Placement and Citation Performance," Plos One 9, no. 10 (October 8, 2014): e109195. doi:10.1371 /journal.pone.0109195.

3. Lara Proud and Susan Murray, "African Published in Scholarly Journals: Open Journal Systems and Alternative Publishing Models used by African Journals Online," Scholarly Publishing in Africa: Opportunities and Impediments, edited by Solani Ngobeni, 185-197 (Pretoria: Africa Institute of South Africa, 2010).

4. Solani Ngobeni, "Scholarly Publishing in South Africa," Scholarly Publishing in Africa: Opportunities and Impediments, edited by Solani Ngobeni, 69-81 (Pretoria: Africa Institute of South Africa, 2010).

5. Matthew J. Smith, Cody Weinberger, Emilio M. Bruna, and Stefano Allesina, "The Scientific Impact of Nations: Journal Placement and Citation Performance," Plos One 9, no. 10 (October 8, 2014): e109195. doi:10.1371 /journal.pone.0109195.

6. Richard Horton, "Medical Journals: Evidence of Bias Against the Diseases of Poverty," The Lancet 361, no. 9359 (3/1, 2003): 712-713. doi:10.1016/S0140-6736(03)12665-7.

7. J. Harle, Foundations for the Future: Supporting the Early Careers of African Re- searchers (British Academy-Association of Commonwealth Universities, 2011).

8. Richard Horton, "Medical Journals: Evidence of Bias Against the Diseases of Poverty," The Lancet 361, no. 9359 (3/1, 2003): 712-713. doi:10.1016 /S0140-6736(03)12665-7.

9. GNK Vukor-Quarshie and Emmanuel Oseifuah, "The Crisis of Publishing in Africa: A Case Study of Selected Countries in Africa," Scholarly Publishing in Africa: Opportunities and Impediments, edited by Solani Ngobeni, 83-98 (Pretoria: Africa Institute of South Africa, 2010).

10. Williams E. Nwagwu, "Open Access Initiatives in Africa-Structure, Incentives and Disincentives," The Journal of Academic Librarianship 39, no. 1 (2013): 3-10. doi:10.1016/j.acalib.2012.11.024.

11. Jennifer I. Papin-Ramcharan and Richard A. Dawe, "Open Access Publishing: A Developing Country View," First Monday 11, no. 6 (2006). http://firstmonday.org/ojs /index.php/fm/article/view/1332/1252.

12. AJoL: www.ajol.info.

13. INASP: www.inasp.info.

14. SciELO: www.scielo.cl.

15. Leslie Chan and Barbara Kirsop, "Open Archiving Opportunities for Developing Countries: Towards Equitable Distribution of Global Knowledge," Ariadne no. 30 (2001), www.ariadne.ac.uk/issue30/oai-chan.

16. Jessica Adamick, Rachel Lewellen, and Rebecca Reznik-Zellen, Library Management of Disciplinary Repositories (Association of Research Libraries, 2013).

17. RePEc: www.repec.org.

18. Williams E. Nwagwu, "Open Access Initiatives in Africa-Structure, Incentives and Disincentives," The Journal of Academic Librarianship 39, no. 1 (2013): 3-10. doi:10.1016/j.acalib.2012.11.024.

19. CGIAR: www.cgiar.org/.

20. Peter Johan Lor and Johannes J. Britz, "Information Imperialism: Moral Problems in Information Flows from South to North," Information Ethics in the Electronic Age, edited by Tom Mendina and Johannes J. Britz, 15-21 (McFarland, 2004). $\pi$ 